\title{
Analysis of the Temporal and Spatial Distribution of Haze and its Influencing Factors in Shanghai
}

\author{
Ma Jing-hui, Mao Zhuo-cheng*, Yu Zhong-qi, Qu Yuan-hao, \\ Geng Fu-hai, Xu Jian-ming, Chen Min
}

Shanghai Meteorological Bureau, Shanghai 200030

Shanghai Key Laboratory of Meteorology and Health

Received: 28 October 2015

Accepted: 9 March 2016

\begin{abstract}
The aim of this paper is to assess the influence of meteorological conditions on the variability of haze in Shanghai during 1981-2013. Based on the observational data of haze and air quality in Shanghai during this period and on the National Centers for Environmental Prediction final analysis data, the long-term variability and the spatial distribution of the haze was analyzed as well as with relationship between haze and atmospheric variables, including visibility, relative humidity, and air quality. Temporal evolution showed that the annual number of haze days in Shanghai represented a rapid decline in the last decade, which was caused by the direct effects of relative humidity and visibility. Global warming-induced changes, such as a warmer temperature, lower relative humidity, and wind speed in winter, were other important factors in the decline. Spatial distribution showed that the annual number of haze days in mid-western Shanghai was higher than those in the southeastern suburbs.
\end{abstract}

Keywords: haze, visibility, relative humidity, climate change

\section{Introduction}

Haze is a type of atmospheric phenomenon where dust, smoke, and dry particles in the air obscure the sky's clarity. Haze is caused by various activities, including farming, traffic pollution, and even wildfires. The World Meteorological Organization (WMO) categorizes the obscuration of the Earth's atmosphere by a list of different types of atmospheric phenomena, including haze, fog, ice fog, steam fog, mist, smoke, volcanic ash, dust, sand, and snow. In addition, the WMO stipulates that relative humidity of fog is usually close to $100 \%$, and that of mist ranges from $95 \%$ to $100 \%$, while that of haze is

*e-mail: 120353998@qq.com below 95\%. The Chinese Meteorological Bureau (CMA) classifies haze as when atmospheric horizontal visibility is less than $10.0 \mathrm{~km}$ due to a large amount of aerosols in the air [1]. The National Office of Disaster Reduction and the Ministry of Civil Affairs first referred to the health hazards caused by haze in natural disaster reports in 2014. One conclusion of IPCC AR5 reports on climate change was that: "human influence on the climate $(>95 \%)$ can explain more than half the rise in global average temperature 19512010." This conclusion again increased the reliability of anthropogenic influence on global warming [1].

In recent decades, extreme weather and climate events have occurred more frequently. Air pollution has become increasingly serious, including the heavy haze events that have occurred frequently over China in recent years. It has a serious impact on human lives and health. Haze consists 
of complex aerosols that not only reduce visibility, but also endanger health due to its toxic and hazardous substances, causing respiratory, cardiovascular, and cerebrovascular diseases.

Research in the 1980s [2-5] and the experiment on tropospheric ozone production about the Spring Equinox (TOPSE) in 2000 [6] provided some of the first comprehensive knowledge about the vertical structure of haze layers, which were found to exist in a huge variety in both vertical (tens of meters to $1 \mathrm{~km}$ thick) and horizontal (20-200 km) directions.

Chinese scholars provided an observational criterion of a hazy day, which pointed out that the revised automatic observations can be used to replace manual observations in order to distinguish fog (mist) from haze [7]. A lot of research identified matters from the spatial-temporal distribution of haze and the influence of climate change [8-10]. This research include source analysis [11-13], numerical simulation $[14,15]$ and aerosol properties analysis [16, 17].

Mass concentration of $\mathrm{PM}_{2.5}$ in eastern China was observed on 1-16 January 2013, and it was found that the weather with high static stability and a high concentration of aerosols was favorable for the formation of haze. It was not completely a natural phenomenon. Instead, it was closely related to human activities [18]. Lian-chun Song [19] had analyzed the regional distribution of haze in China (1961-2012) and found that southern and northern China and the middle and lower reaches of the Yangtze River had experienced increases of days of haze, while northeastern, east-northwestern, and east-southwestern China showed a decreasing trend. At present, China has four regions with frequently occurring haze events: Beijing-Tianjin-Hebei, the Yangtze River Delta, the Pearl River Delta, and the Sichuan Basin $[1,20]$.

The results of research on the effect of climate change on future pollution $[21,22]$ do not inspire optimism. Simulations of winter weather conditions and air quality for central and southeastern Europe by [23] demonstrated that climate change will be followed by deteriorated air quality, not only due to potentially increased $\mathrm{O}_{3}$ concentrations, but also as a result of an expected growth in $\mathrm{SO}_{2}$ concentration levels, with relatively low changes in $\mathrm{PM}_{10}$ concentrations. Methods for tackling these negative trends include restructuring of urban space and amelioration of the tropospheric climate of the city.

As a representative city in the Yangtze River Delta, Shanghai has experienced rapid industrialization, which has lead to a huge increase of vehicles and industrial emissions. Hence haze has become one of the typical severe weather phenomena in Shanghai. It affected the sustainability of the development of an urban environment. Under the background of global warming, the climate in eastern China has undergone a significant change. Hence the observational study on the temporal and spatial distribution of haze in Shanghai is particularly important for exploring the weather factors of haze formations. Research on the effects of climate change on the future development trend of haze $[21,22]$ did not inspire an optimistic picture. This paper attempts to analyze the long-term variability and the spatial distribution of haze in Shanghai and identify the relationships between meteorological elements and haze variability.

\section{Data and Methods}

For this paper we used surface meteorological observations in Shanghai during 1981-2013, including haze, visibility, and relative humidity data, as well as the $\mathrm{PM}_{10}$ data from the Shanghai Environmental Monitoring Center. According to the criterion of haze from the "observation and prediction level of haze" [24], it could be divided into four levels: low-slight haze (visibility 5-10 km), slight haze (visibility 3-5 km), moderate haze (visibility $2-3 \mathrm{~km}$ ), and heavy haze (visibility $1-2 \mathrm{~km}$ ). National Centers for Environmental Prediction final analysis data showed six hourly $1^{\circ} * 1^{\circ}$, and global reanalysis data were used for meteorological analysis.

\section{Results}

\section{Inter Annual Variability of Haze}

Fig. 1 shows that the number of haze days in Shanghai was abnormally high from 2001 to 2004. This was determined by using an automatic weather station visibility meter (VAISALA PWD20, Finland). Automatic observations of visibility were significantly lower [25] than manual observations of visibility, which caused an increase in haze days. A Guassian filter was used to smooth the time series of the annual number of haze days and to determine the long-term haze day number (dotted line in Fig. 1). The results showed that Shanghai's annual number of haze days could be separated into four distinct stages. The first stage (1981-1994) had a significant increasing linear trend of $34.5 \mathrm{~d} / 10 \mathrm{a}$. This was inseparable from the rapid development of Shanghai's economy along with an exploding population and increasing pollutant emissions [26]. This stage was the critical period of Shanghai developing from economic recovery to the reform and opening-up period. With an increasing population and motor vehicle numbers, haze days showed an increasing trend year by year. In the second stage (1995-2002), the number of haze days showed a rapidly increasing linear trend of $31.5 \mathrm{~d} / 1 \mathrm{a}$. During this period, Shanghai was in the comprehensively advancing and rapid development stage of reform and opening-up, with accompanying rapid economic development, city expansion, and a rapidly increasing population with car ownership reaching more than 6.5 million by January 2003, which of course led to greater air pollution and more frequent haze events.

In the third stage (2003-2010), the number of haze days significantly decreased from 229d in 2003 to 39d in 2010 (at the average level of the 1980s and 1990s), with the annual growth rate of $-23.7 \mathrm{~d} / 1 \mathrm{a}$. This stage was from the time that Shanghai successfully bid to host the World 


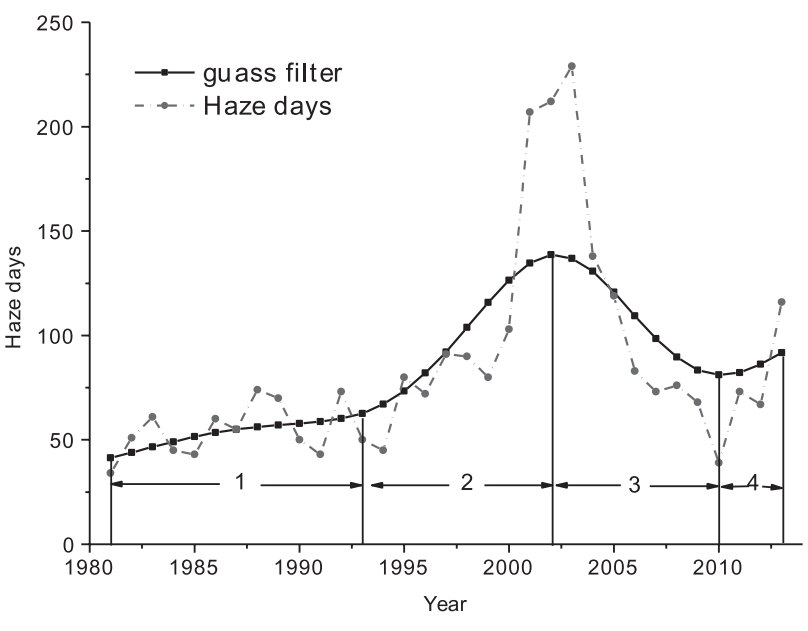

Fig. 1. Annual variation of haze days and guass filter in Shanghai, 1981-2013.

Expo. In order to ensure air quality during that event, Jiangsu, Zhejiang, and Shanghai jointly implemented the air pollution prevention and control measures in the YRD region for the World Expo by spreading measures and constraining emissions of polluting enterprises in the region within a radius of $300 \mathrm{~km}$ around the expo site. The air quality during the expo created a record of clean air as a result of this solid foundation, with the number of haze days reaching the lowest point in the previous decade. This could be seen from the annual change of $\mathrm{PM}_{10}$ annual average concentration from 2001 to 2013 (Fig. 2) where, before 2010, the $\mathrm{PM}_{10}$ partial index showed a linear downward trend, revealing the effect of energy savings and emissions reduction. In the fourth stage (2011-13), haze days again showed an increasing trend, from $40 \mathrm{~d}$ in 2011 to $116 \mathrm{~d}$ in 2013. The $\mathrm{PM}_{10}$ sub-index also rose after 2011. This had a close relationship with resuming production of once-closed factories at the end of the world expo.

The tendencies of the carbon emissions and the $\mathrm{SO}_{2}$ emissions from 2001 were shown clearly in Fig. 3. Specifically, carbon emissions revealed a dramatically

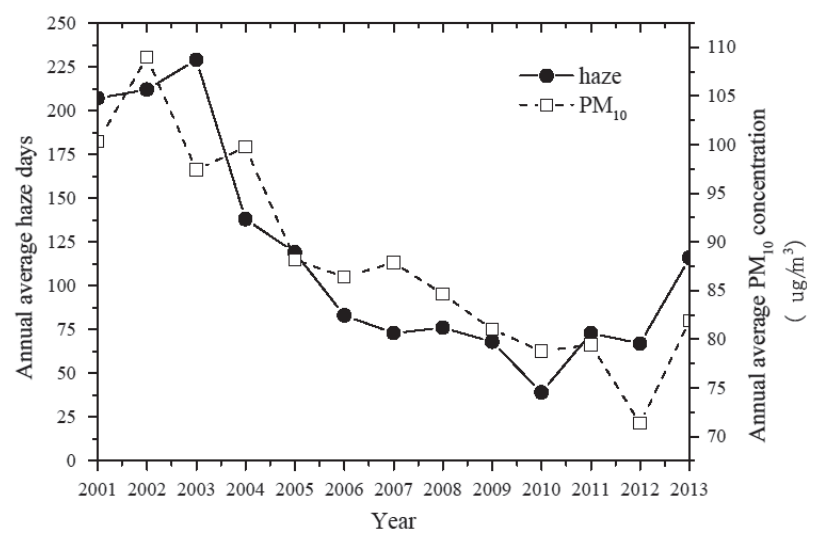

Fig. 2. Annual average $\mathrm{PM}_{10}$ concentrations and haze days, 2001-13.

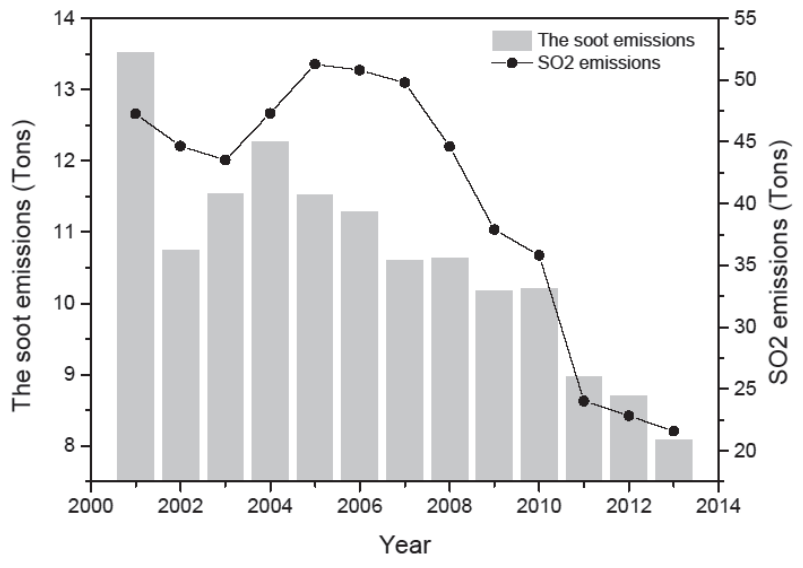

Fig. 3. Average soot emissions and $\mathrm{SO}_{2}$ emissions in Shanghai, 2001-13.

decreasing trend from 12.27 tons in 2004 to 8.09 tons in 2013, which reflected a 34\% decrease during this nine-year period. Meanwhile, $\mathrm{SO}_{2}$ emissions also decreased after 2005, which presented a more obvious downtrend even after 2007. $\mathrm{SO}_{2}$ emissions were reduced from 49.78 tons in 2007 to 21.58 tons in 2013, with an approximately $56 \%$ deduction. In addition, one point that should be emphasized was that the declining rate of $\mathrm{SO}_{2}$ emissions was much greater than the declining rate of carbon emissions. As a matter of fact, the emissions were controlled and reduced and the technique of desulfurization was applied well.

Fig. 4 shows that the large monthly numbers of haze days in Shanghai mainly occur in the first half of the year. Before 1995, it shows a trend of steady oscillation, and the number of haze days is maintained at between 5 and 40 days. The monthly variation shows an obvious seasonal transition of haze days, which occurred more frequently in winter than summer, and the same in spring and autumn. This characteristic of seasonal variation is coincident with atmospheric pollution, as the diffusion conditions for atmospheric pollutants are worse in winter than other seasons. With lower mixing layer height and less rainfall, pollutants are easy to accumulate in the air and more prone to form haze. In summer, the diffusion conditions for pollutants is quite sufficient due to the increases of mixing layer height and precipitation. Dilution and diffusion of atmospheric pollutants are hence enhanced, resulting in improved atmospheric visibility and the chance of haze is reduced. Weather conditions in autumn and spring are in the transitional period of summer and winter, with almost the same diffusing capability for pollutants. So the air pollution and haze in spring and autumn has a similar occurrence rate [26]. At the same time, monthly distribution of haze days showed obvious inter-annual variability. The number of haze days shows a decreasing trend in February and April from 2004 to 2012, and a significant increase is found in 2013.

Monthly variation of haze during the first half of the year is closely related to atmospheric circulation. Cold air outbreaks more frequently over the north in the first half 


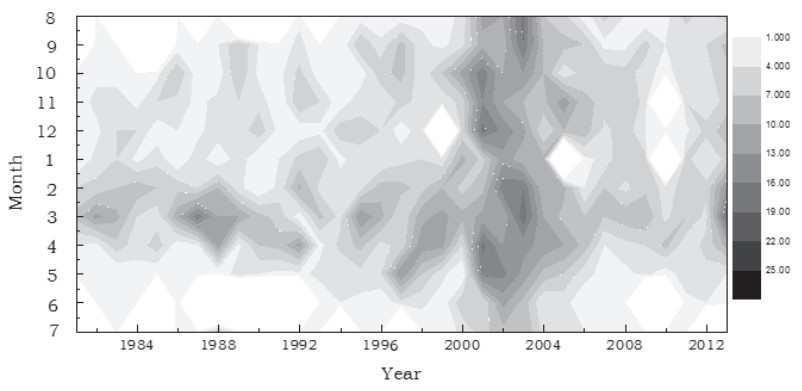

Fig. 4. Annual variation in the number of haze days at different levels in Shanghai during 1981-2013.

of the year. The Pacific subtropical high moves northward slowly, with cold and warm air confronting each other for a long time. That makes it easy to generate a modified high pressure area in Shanghai, and there is downdraft in the areas controlled by modified high pressure. Wind velocity is small, so the transportation and diffusion of air pollutants were restrained in the subsidence area, causing accumulation of pollutants. In the second half of the year the atmospheric circulation situation shows an opposite trend, when a subtropical high moves southward rapidly, and cold air outbreaks with a strong intensity, causing a strengthened horizontal wind and better diffusion conditions, thus reducing the number of haze days. From October to December, the Siberian cold high-pressure area begins to retract southward and gradually control most of China. Under this high pressure the weather is sunny and cloudless, along with small wind speed and sinking airflow. With an increasing consumption of heating coal in northern China, the pollutants are not easy to spread and have certain transport to Shanghai through a low-level flow. As a result, the number of haze days appears to first decrease and then increase.

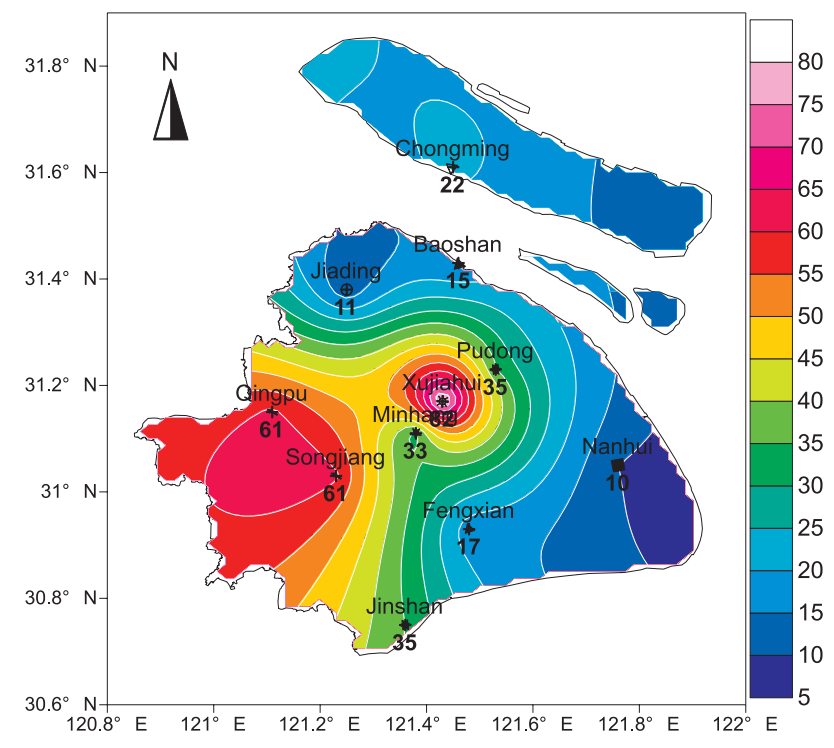

Fig. 5. As in Fig. 4, but for average annual haze days in spatial distribution.
From the 33-year averaged spatial distribution of the annual number shown in Fig. 5, the variability of Shanghai haze in spatial distribution is dramatic, with more occurrences in western suburbs and the central city, and fewer in the southeastern suburbs. The largest number of haze days is 82 at downtown Xujiahui Station, whereas the smallest is 10 days in the southeastern suburbs of Nanhui. That is a 72-day difference between the most (Xujiahui) and the least (Nanhui) haze days, so the densely populated city center has a great impact on the occurrence of haze. In western suburbs (Qingpu, Songjiang Station) the annual average number of haze days is 61-50 more than in the eastern suburbs. The main reason is that the western suburbs are close to the inland areas, where the urban agglomerate is upstream and the sea breeze reaches deep inland. Those factors increase the probability of local convergence in the center of the city [27].

\section{Visibility, Relative Humidity, Wind Speed, and Evolution Characteristics}

It can be seen from Fig. 6 that the visibility of haze days is lower than the no-haze days in each year. The average visibility of haze days is $3 \mathrm{~km}$ lower than no-haze days. Generally, visibility on either haze days or no-haze days are on the rise. It falls to the lowest in 1992-94, and the recent 10 years shows a trend of rapid increase. The visibility of no-haze days has improved significantly over haze days.

The annual mean relative humidity in Shanghai generally shows a downward trend year by year (Fig. 7). Annual mean relative humidity before 2000 is higher than the average relative humidity of $76 \%$ for many years, with a relatively weak decrease. After 2000, the annual average relative humidity drops fast, and is lower than the average relative humidity for many years (falling at a rate of about 1\%/a). The minimum occurs in 2011, when the annual average relative humidity is only $62.6 \%$. The average relative humidity on haze days is lower

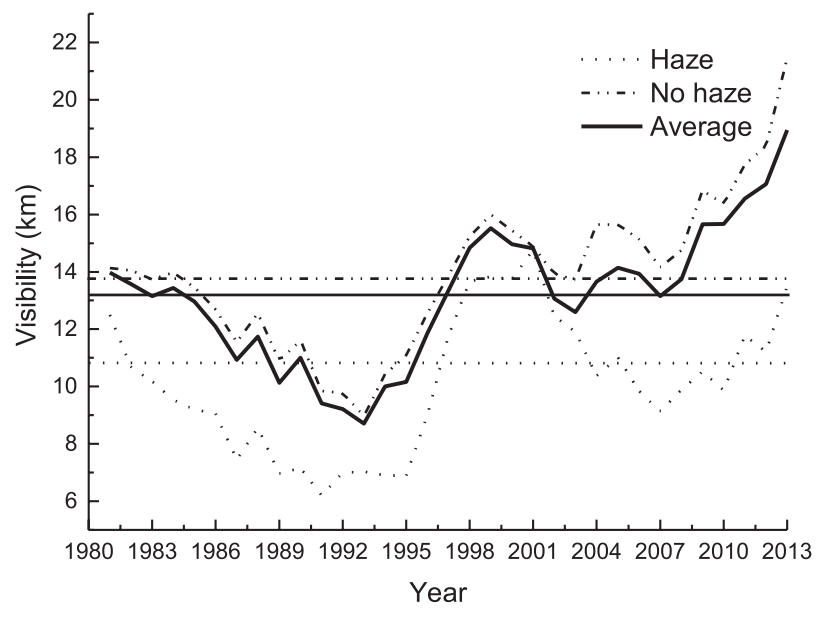

Fig. 6. As in Fig. 4, but for visibility variation. 


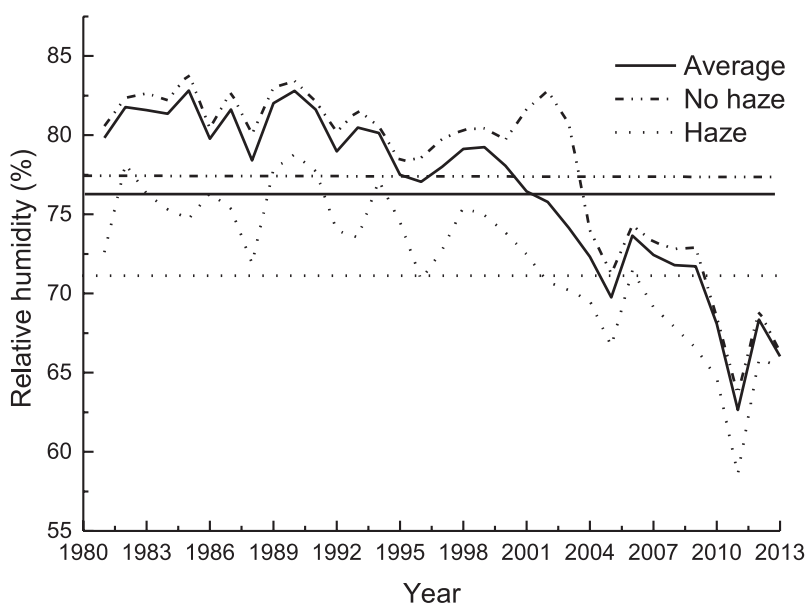

Fig. 7. As in Fig. 4, but for relative humidity variation.

than the other days, so haze mainly occurs in a drier environment. Another noteworthy phenomenon is that, after 2000, the variation of relative humidity is opposite that of visibility over time. Visibility generally rises year by year, whereas relative humidity is on the decline. Possible reasons for this phenomenon will be discussed at length later.

It can be seen from Fig. 8 that for the past 33 years, annual average wind speed has undergone a significant fluctuation. The late 1980s experienced a low-speed wind period. The trend of annual average wind speed was reduced in the last decade. Annual average wind speed on haze days was $0.8 \mathrm{~m} / \mathrm{s}$ lower than no-haze days, and $0.6 \mathrm{~m} / \mathrm{s}$ lower than the annual average wind speed. Haze mainly occurred with small wind speed and high static stability. While in the last decade wind speed decreased and the number of haze days also showed a declining trend. Annual average wind speed is not the only factor that influences the number of haze days. Improvement of air quality and the decline of relative humidity are probably the key reasons.

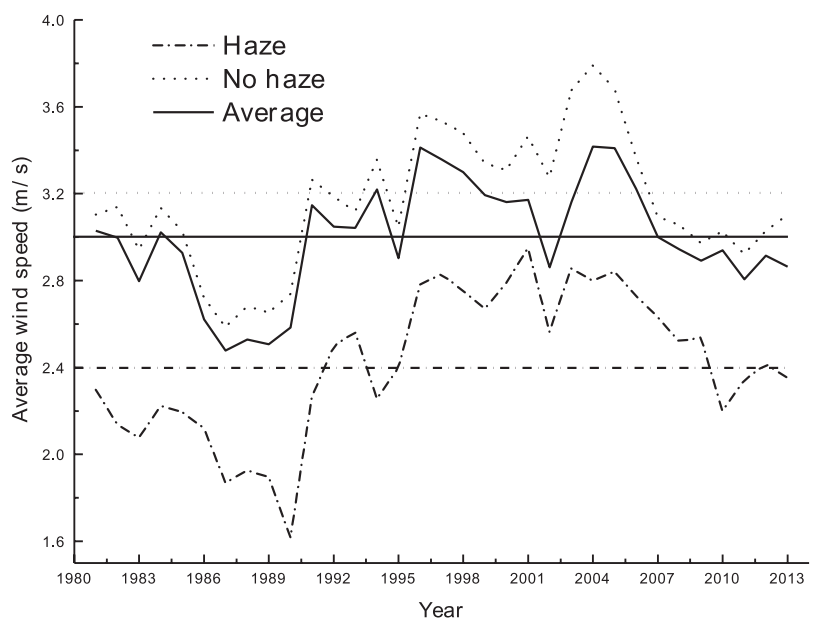

Fig. 8. As in Fig.3, but for wind speed variation.

\section{The Characteristics of Maximum Relative Humidity Variation Year by Year and $\mathrm{M}-\mathrm{K}$ Test}

It is well known that hygroscopic growth of particulate matter is one of the main factors that affects visibility and is the main mechanism affecting haze. The decrease of haze days and the increase in visibility since 2004, in addition to energy savings and emissions reduction, cause a decrease in pollutants. Relative humidity, which causes a decrease in particulate matter and hygroscopic growth, also has a certain effect. Fig. 9 shows that maximum annual mean relative humidity in Shanghai in the last decade has been in a significant decline, consistent with the tendency of the annual change in haze days (Fig.1). It can be seen from the UF and UB statistics curve of maximum relative humidity (Fig. 10) in many years that mutation occurs in 2004 , then this decrease trend gradually becomes obvious. Significance level test also exceeded the 0.001 threshold

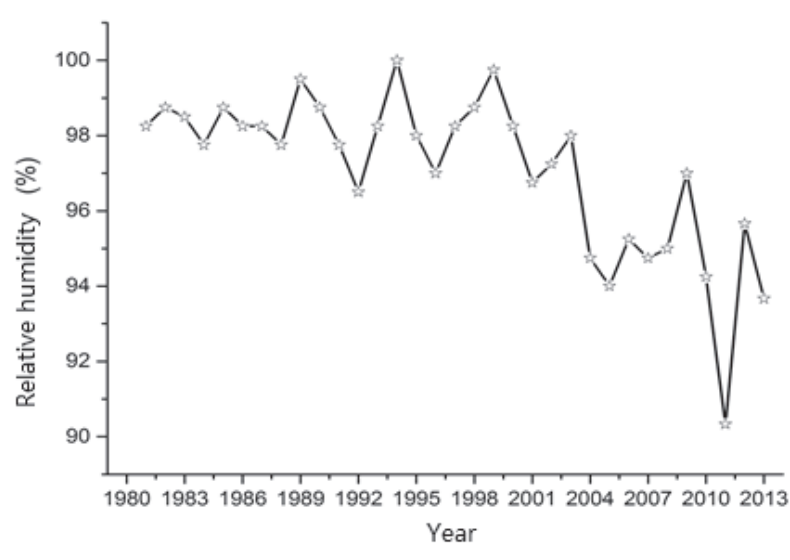

Fig. 9. As in Fig. 4, but for daily average relative humidity changes.

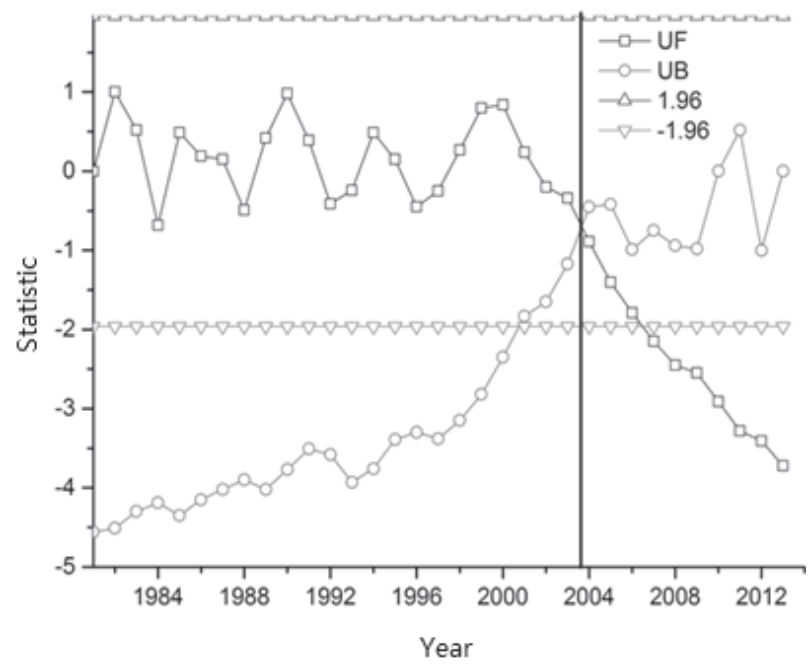

Fig. 10. As in Fig. 3, but for daily average relative humidity M-K test of shanghai. 


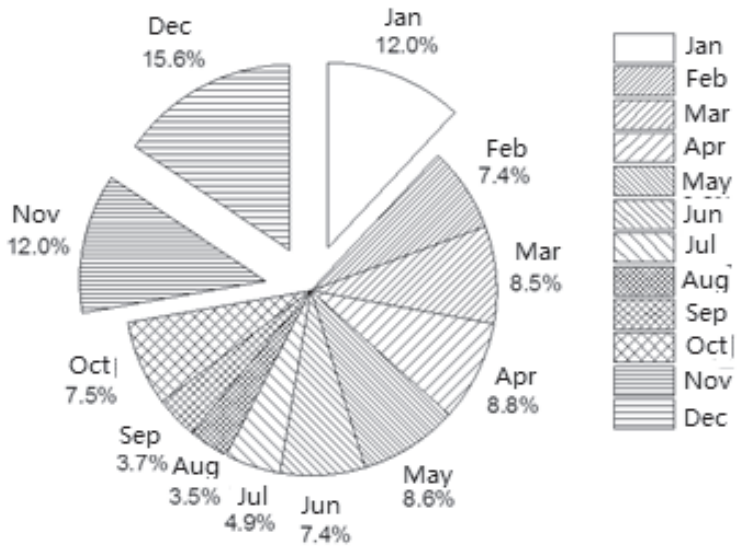

Fig. 11. Months of haze in Shanghai.

$(\mathrm{u} 0.001=2.56)$ from 2007 to 2013 . The results show that maximum relative humidity declined significantly in the last decade.

\section{Climate Impact Factor Analysis}

As the results in section 2.3 show, the annual mean maximum relative humidity exhibits a downward trend year by year after 2004. Is this related to climate change?

a)

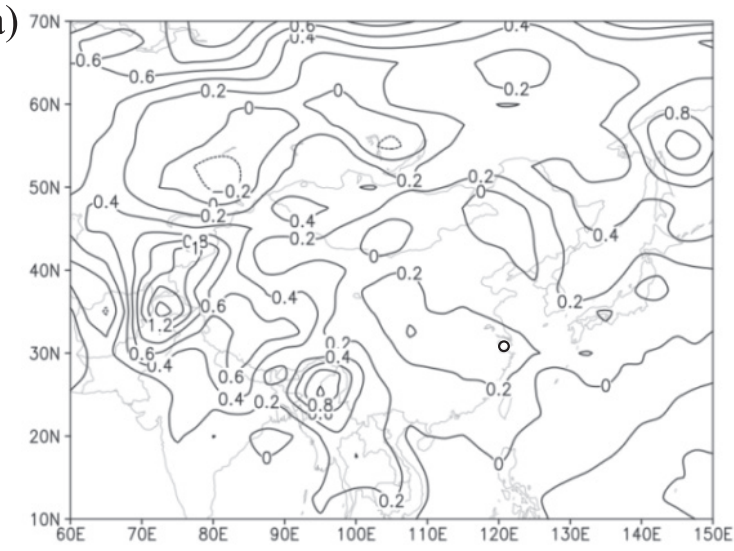

b)

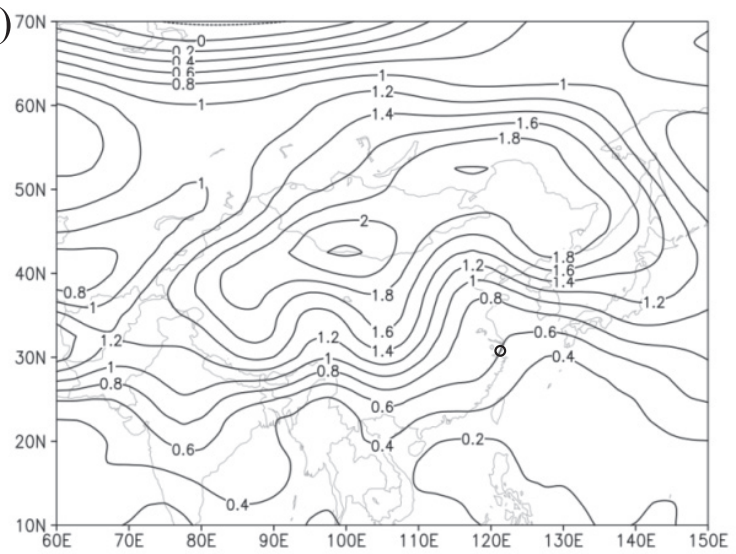

Fig. 12. Annual average temperature departure from 2004 to 2013 at $1,000 \mathrm{hPa}$ a) and b) $850 \mathrm{hPa}$ from 1948 to 2003 (the red dot is Shanghai).
Fig. 11 shows the haze days accounts for nearly $40 \%$ of total annual haze days in winter. The evolution of the circulation background in winter and the related factors in the last decade are analyzed to explain the decrease of relative humidity from the point of view of climate change, which demonstrates the changes of haze.

\section{Temperature Departure}

Fig. 12 shows the annual average temperature at 1,000 hpa and 850 hpa departure from 2004 to 2013. It can be seen that the temperature of the central and eastern regions exhibits a significant positive anomaly. The temperatures for 1,000 hpa and $850 \mathrm{hpa}$ in Shanghai in the most recent decade are $0.2^{\circ} \mathrm{C}$ and $0.6^{\circ} \mathrm{C}$ higher, respectively. Fig. 13(a, b) shows that the winter temperature departure at $1,000 \mathrm{hpa}$ is not significant, and the $850 \mathrm{hpa}$ temperature is $0.25^{\circ} \mathrm{C}$ lower. Although the low level temperature in Shanghai has been high overall in the last decade, it is lower than usual in winter. Climate warming in China during the last 50 years is not only contributed to by human activity, but also by urbanization, natural periodicity and decadal variability, the dimming and brightening of solar radiation, and other factors such as solar activity, volcanic activity, and interactions inside the climate system [2830]. Most climate scientists agree that the last 50 years

a)

b)
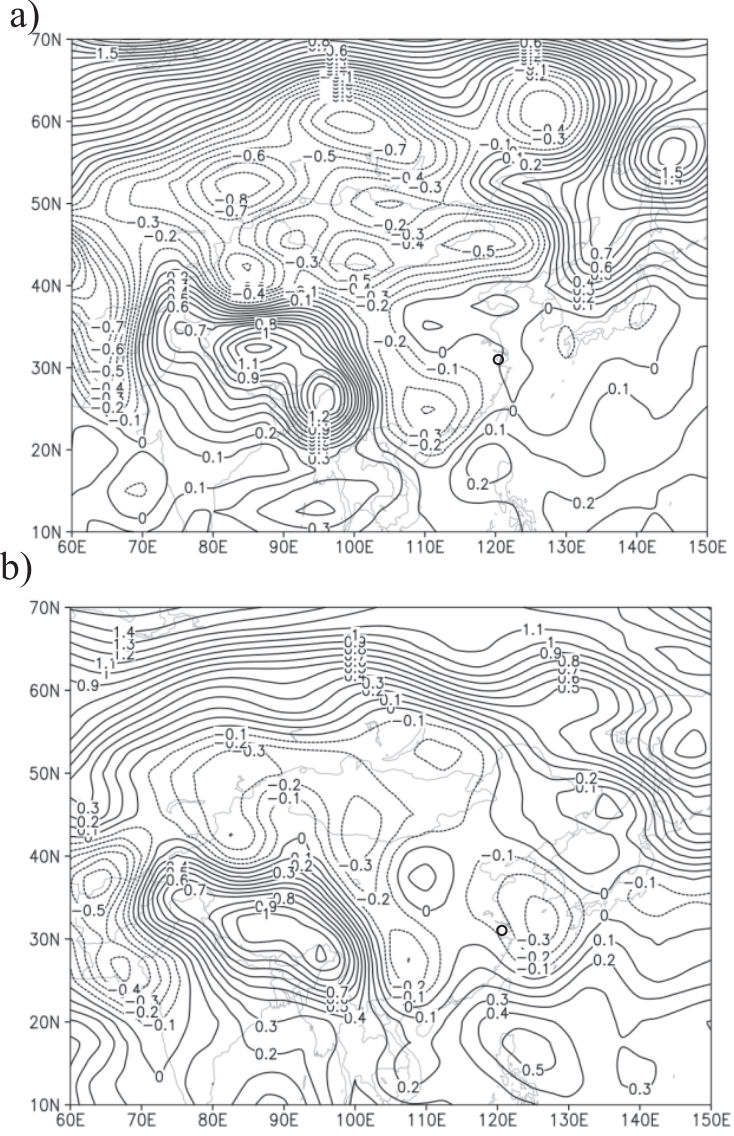

Fig. 13. a) Average temperature anomaly at $1,000 \mathrm{hPa}$ (January, November, December) from 2004 to 2013, and b) at $850 \mathrm{hpa}$ from 1948 to 2003 (the red dot is Shanghai). 
of Chinese climate warming is most likely mainly caused by the increased concentrations of greenhouse gases [31]. So it is not conducive to maintaining the static stability of weather and haze, which is one possible reason for the decline of haze days in the past 10 years.

\section{Low-level Wind Field Departure}

It can be seen from annual average wind anomaly at $1,000 \mathrm{hPa}$ and $850 \mathrm{hPa}$ in the last decade from Fig. 14 that southerly and southeasterly winds increased significantly in mid-eastern regions, especially the southerly wind on the east coast of China. As shown in the winter departure in Fig. 15, southerly wind increased slightly at $1,000 \mathrm{hPa}$ and $850 \mathrm{hPa}$. The southerly low-level wind in Shanghai increased in the last decade. It is known that in Shanghai, northerly winds could easily bring air pollution, and the increase in southerly wind was not sufficient for the divergence of haze. This is one possible factor that has helped reduce haze days in the past 10 years.

\section{1,000 hPa Relative Humidity Departure}

In the past decade, eastern China's relative humidity exhibited a significant negative departure, particularly in

a)

b)
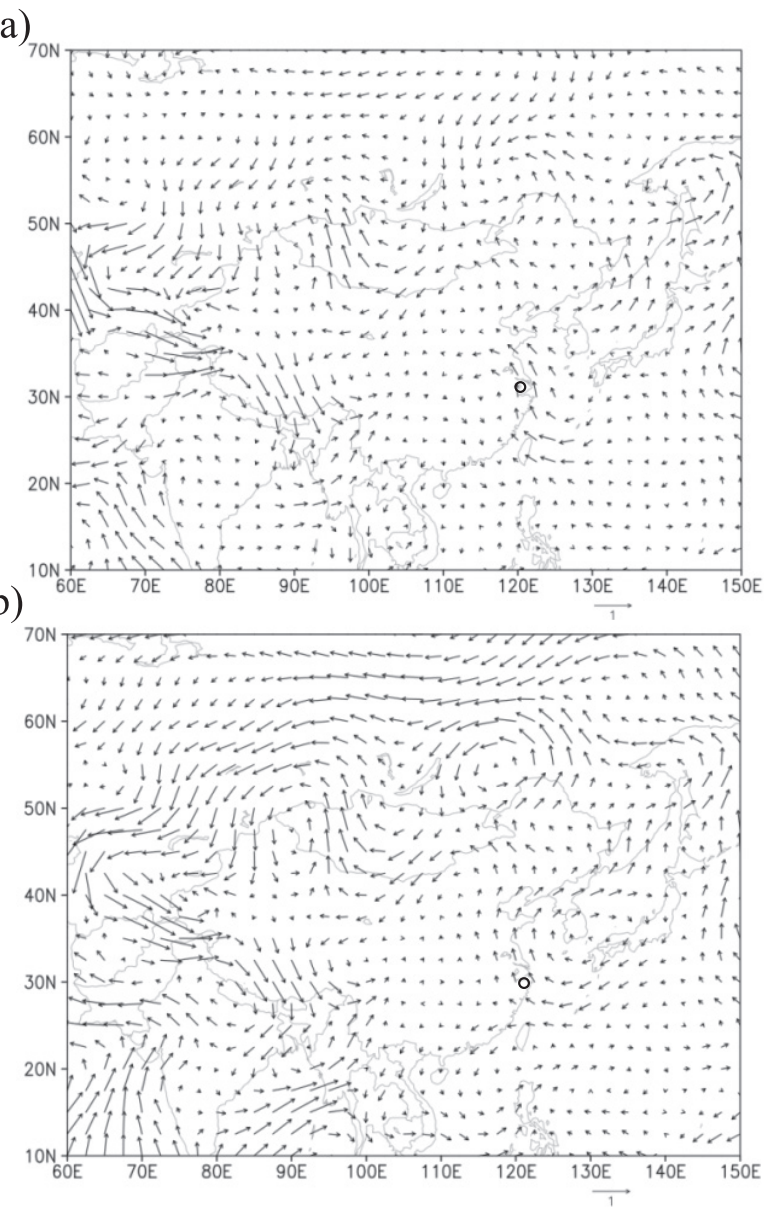

Fig. 14. As in Fig. 12, but for annual average of wind anomaly (the red dot Shanghai). winter. Relative humidity of Shanghai fell by $2-3 \%$ in the last decade (Fig. 16a), and reached $4 \%$ in winter. The change of aerosol extinction coefficient mainly depends on the size of the aerosol particles, and relative humidity is the main factor that increased the size of aerosol particles by hygroscopic growth [32]. As a result, relative humidity has decreased in the last decade, especially in winter (Fig. $16 \mathrm{~b}$ ), and the effect of hygroscopic growth of the aerosol particles is reduced, thus leading to a reduction in visibility and an increase in haze events.

Therefore, in the last decade climate change is one cause of the reduction of haze days. Climate warming, winter wind abating, and relative humidity drop are all linked to the increased visibility in the Shanghai area. As a result, climate background may be another factor affecting haze.

\section{Conclusion and Discussion}

Based on 33 years of haze observation data in Shanghai, this paper analyzed the temporal variation and spatial distribution characteristics of haze in the Shanghai area. Combined with the global National Centers for Environmental Prediction reanalysis data, we analyzed the
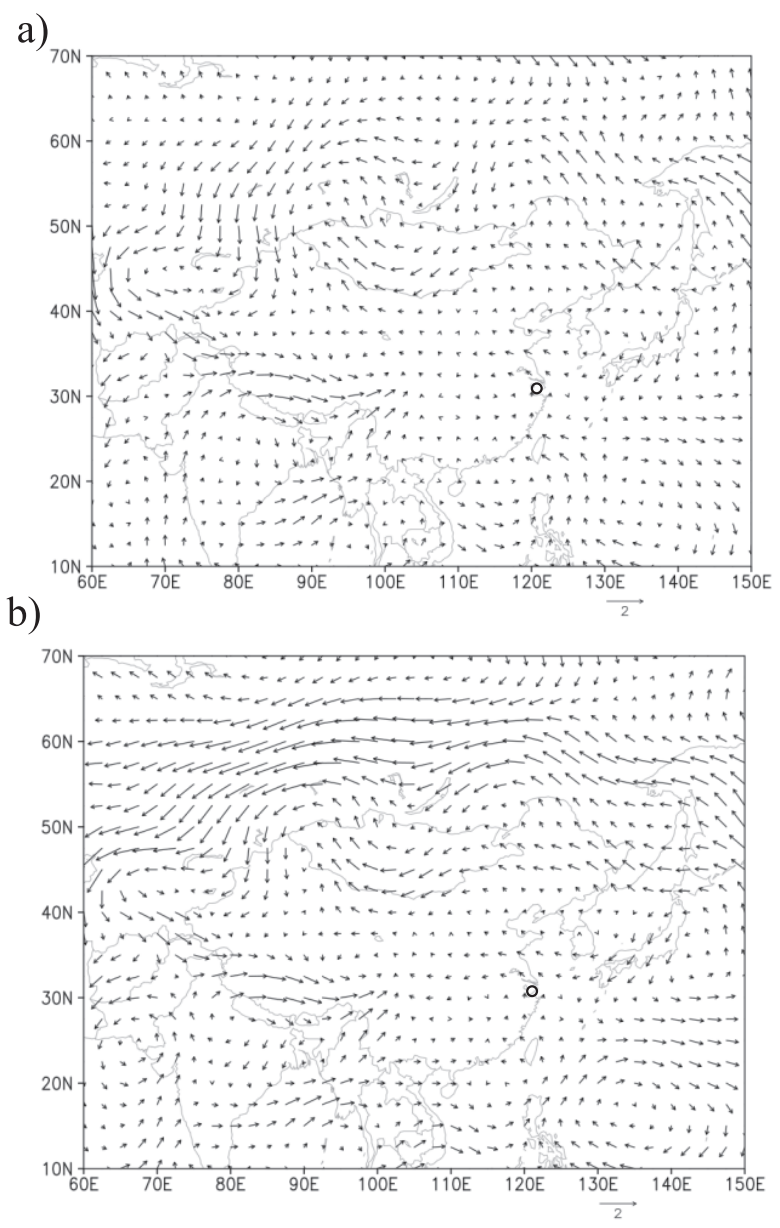

Fig. 15. As in Fig. 12, but for average wind anomaly of winter from 1948 to 2003 (the red dot is Shanghai). 

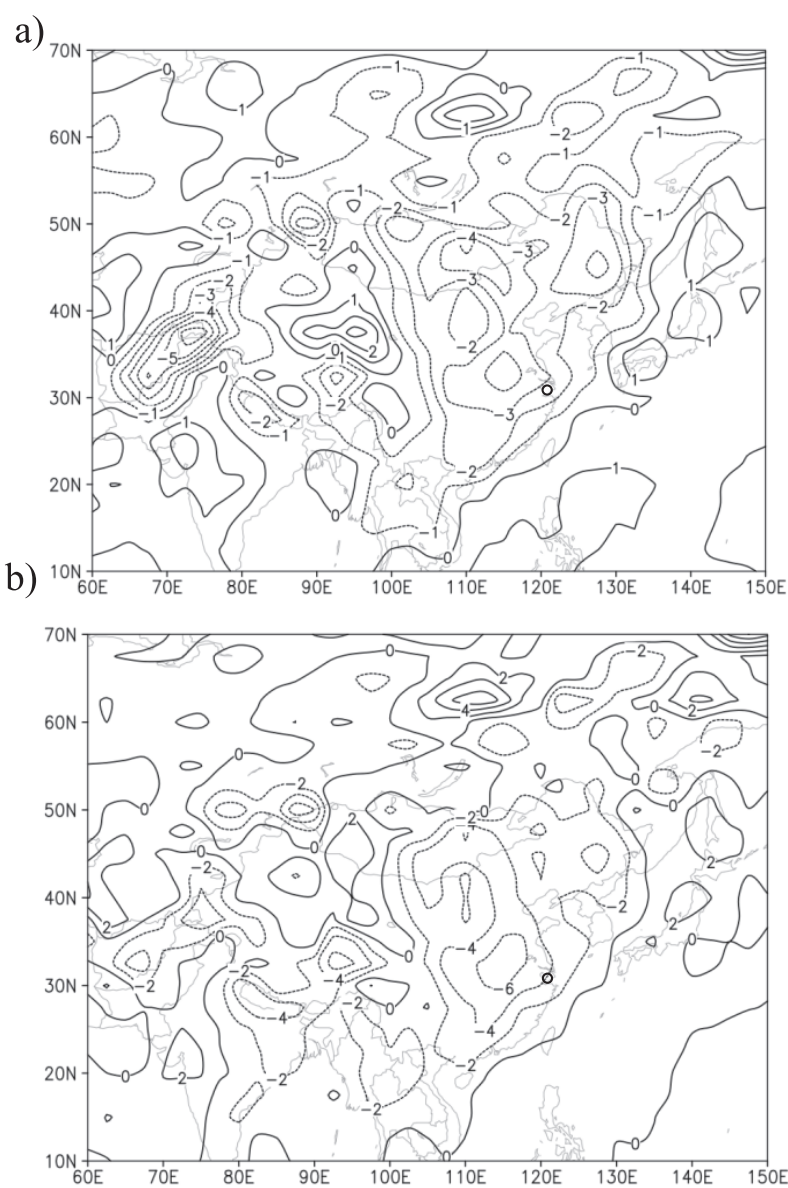

Fig. 16. a) Annual average relative humidity anomaly at $1,000 \mathrm{hPa}$ from 2004 to 2013, and b) average relative humidity anomaly in winter at $1,000 \mathrm{hPa}$ from 1948 to 2003 (the red dot is Shanghai).

yearly variation of haze days, and comparatively analyzed the meteorological elements and climate background that may cause changes in haze days. The research shows that:

1. The annual number of haze days in Shanghai from 1981 to 2013 showed trends of significant variations, including four stages: rising steadily before 1999, rising rapidly from 2000 to 2004 (which may be associated with the visibility observation automating business), decreasing significantly from 2004 to 2010 (which has a close relationship with climate change and the joint prevention and control of atmospheric pollution for the World Expo in Shanghai), and increasing significantly from 2010 to 2013.

2. The distribution of annual average haze days shows more in mid-western Shanghai and less in the northern and southeastern suburbs. This is associated with the presence of upstream urban agglomeration transport and land-sea wind convergence in the central city, as well as huge urban population density and large pollutant emissions.

3. Haze causes atmospheric horizontal visibility to be reduced markedly, with the average of daily visibility on haze days $3 \mathrm{~km}$ less than on days without haze. The most recent 20 years of Shanghai's average visibility exhibit a significant rising trend, in contrast to the relative humidity change tendency. The annual average wind speed on haze days is $0.8 \mathrm{~m} / \mathrm{s}$ less than that on days without haze. Weather in high static stability is more likely to result in an increase of haze days.

4. In the last decade, the surface layer temperature has risen significantly in Shanghai. A significant reduction of the relative humidity and the winter wind leads to increased visibility, and thus causes a reduction in haze days. Therefore, climate change is probably another major factor affecting haze.

\section{Acknowledgements}

This research is supported by Special fund of China Meteorological Bureau, No. CMAYBY2014-022, Special Research Project Funds of Shanghai (No.14DZ1202904) and Special Funds for Climate Change of China Meteorological Administration (No. CCSF201503).

\section{References}

1. WANG S.W., LUO Y., ZHAO Z.C., WEN X., HUANG J. The Fifth IPCC Assessment Report Hits the Streets[J]. Progressus Inquisitiones De Mutatione Climatis, 9 (6), 436, 2013.

2. SCHNELL F.W. Modelling basic epistasis for quantitativegenetic studies. Vortr Pflanzenzüchtg 7, 1-11, 1984.

3. RADKE M., WILLSCH H., WELTE D.H. Class separation of aromatic compounds in rock extracts and fossil fuels by liquid chromatography. Analytical Chemistry, 56, 2538, 1984.

4. LEAITCH W.R., HOFF R.M., MACPHERSON J.L. Airborne and Lidar measurements of aerosol and cloud particles in the troposphere over Alert Canada in April 1986. nuliJ. Atmos. Chem. 9 (1-3), 187, 1989.

5. BROCK C.A., RADKE L.F., LYONS J.H., HOBBS P.V. Arctic hazes in summer over Greenland and the North American Arctic, I, Incidence and origins. J. Atmos. Chem. 9, 129, 1989.

6. ATLAS E.L., RIDLEY B.A., CANTRELL C., The Tropospheric Ozone Production about the Spring Equinox (TOPSE) Experiment: Introduction, J. Geophys. Res., doi:10.1029/2002JD003172, 108, 8353, 2003.

7. SONG WENYING MEI Shilong and SUN Hua.Study and discuss about observation criterion of grey haze based on automatic station data.Journal of the Meteorological Sciences, 32 (1), 74-79, 2012 [In Chinese].

8. GAO G.E. The Climatic Characteristics and Change of Haze Days over China during 1961-2005 [J]. Acta Geographica Sinica, 63 (7), 761, 2008 [In Chinese].

9. WU MENG, FAN SHAOJIA, WU DUI, BT LIAO, LI HAIYAN Characteristics and influence factors study of haze and cleaning weather over Guangzhou Area [J]. China Environmental Science, 32 (8), 1409, 2012 [In Chinese].

10. ZHAO P.S., XU X.F., MENG W., DONG F., HE D., SHI Q.F., ZHANG X.L. Characteristics of hazy days in the region of Beijing, Tianjin, and Hebei[J].China Environmental Science, 32 (1), 31, 2012 [In Chinese]. 
11. LIU YONGHONG., FENG TING., CAI MING. Characteristics of the haze phenomenon in Guangzhou[J]. Research of environmental sciences, 24 (10), 1081, 2011 [In Chinese].

12. DING Y.H., LIU Y.J. Analysis of long-term variations of fog and haze in China in recent 50 years and their relations with atmospheric humidity. Science China: Earth Sciences, 57, 36, 2014 [In Chinese], doi: 10.1007/s11430-013-4792-1

13. WANG LITAO, PAN XUEMEI, ZHENG JIA, CHENG DANDAN, WEI WEI A modeling study of the regional haze over Hebei and surrounding areas [J]. Acta Scientiae Circumstantiae, 32 (4), 925, 2012 [In Chinese].

14. HU R.Z., LIU H.N., ZHANG M.G., JIANG W. Simulation of brownish haze in urban areas of Nanjing[J], Acta Scientiae Circum stantiae, 29 (4), 808, 2009 [In Chinese].

15. AN J.L., LI Y., CHEN Y., LI J., QU Y., TANG Y.J. Enhancements of major aerosol components due to additional HONO sources in the North China Plain (NCP) and implications for visibility and haze $[\mathrm{J}]$. Advances in Atmospheric Sciences, 30 (1), 57, 2013.

16. LIU Q., GENG F.H., CHEN Y.H., TING-TING X.U., HUA Z., HU P., MAO X.Q. Vertical distribution of aerosols during different intense dry haze periods around Shanghai [J]. China Environmental Science, 32 (2), 207, 2012 [In Chinese].

17. WANG J., NIU S.J., DAN X.U., XING-NA Y.U. Aerosol optical properties during the typical haze/fog event in Nanjing[J]. China Environmental Science, 33 (2), 201, 2013 [In Chinese].

18. ZHANG X.Y., SUN J.Y., WANG Y.Q., LI W.J., ZHANG Q., WANG W.G.,QUAN Q.N., CAO G.L.,WANG J.Z., YANG Y.Q., ZHANG Y.M. Factors contributing to haze and fog in China. Chin Sci Bull (Chin Ver), 58, 1178, 2013, doi: 10.1360/972013-150.

19. SONG L.C., GAO R., LI Y., WANG G., CENTER N.C. Analysis of China's Haze Days in Winter Half Year and Climatic Background During 1961-2012 [J]. Advances in Climate Change Research, 9 (5), 313, 2013 [In Chinese].

20. WANG M.J., ZHU X.Y., CHEN S.P. Characteristics of haze weathers with different level in Shenzhen during 19812010[J]. China Environmental Science, 33 (9), 1563, 2013 [In Chinese].

21. GIORGI F., MELEUX F. Modeling the regional effects of climate change on air quality. C.R. Geoscience, 339, 721, 2007.10. GX/T113-2010, Observation and forecasting levels of haze[S].
22. JACOB DANIEL J., DARREL A. WINNER. Effect of climate change on air quality. Atmospheric Environment $\mathbf{4 3}$ (1), 51, 2009.

23. HUSZAR P., HALENKA T., BELDA M., et al. Regional climate model assessment of the urban land-surface forcing over central Europe[J]. Atmospheric Chemistry \& Physics, 14 (12), 18541, 2014.

24. Meteorological industry standard of the People's Republic of China, Observation and forecasting levels of haze, GX/ T113-2010.

25. YANG Y.X., HU X.H., MIRIAM P.W. D20 visibility and com parative analysis of visibility and visual[J]. Journal of Lanzhou University (Natural Sciences), 45, 62, 2009 [In Chinese].

26. REN Z., FUQING S.U., CHEN Z., HONG Z., CHENG S., GAO Q. Innuence of synoptic systems on the distributioll and evolution process of PM10 concentration in the boundary layer in summer and autumn. Chinese Journal of Atmospheric Sciences 32 (4), 741, 2008 [In Chinese].

27. JIANG W.M.,SUN J.N.,CAO W.J., JIANG R.B. Air pollution meteorology tutorial[M]. Beijing: china meteorological press [In Chinese], 2004-03 ISBN-750291318.

28. YE DUZHENG, FU CONGBIN, DONG WENJIE, WEN GANG, YAN XIAODONG Progresses in Studies of global change sciences [J]. Atmospheric Science, 27 (4), 435, 2003.

29. IPCC. Climate Change 2007 - The Physical Science Basis, Contribution of Working Group I to the Third Assessment Report of the IPCC [ C] .Solomon S, Qin D, eds. Cambridge: Cambridge University Press, 996, 2007.

30. REN GUO-YU, CHU ZI-YING, ZHOU YA-QING, XU MING-ZHI, WANG YING, TANG GUO-LI, ZHAI PANMAO, SHAO XUE-MEI, ZHANG AI-YING, CHEN ZHENG-HONG, GUO JUN, LIU HONG-BIN, ZHOU JIANG-XING, ZHAO ZONG-CI, ZHANG LI, BAI HU-ZHI, LIU XUE-FENG, TANG HONG-YU Recent Progresses in Studies of Regional Temperature Changes in China[J].Climatic and Environmental Research [J]. Climate and Environmental Research, 10 (4), 701, 2005 [In Chinese].

31. IPCC. Climate change 2001: The scientific basis contribution of working group I to the third assessment report of the IPCC [C]. HOUGHTON J.T., DING Y.H., et al, eds. Climate Change 2001. Cambridge: Cambridge University Press, 2001.

32. PAN X.L., YAN P., TANG J. Observational study of influence of aerosol hygroscopic growth on scattering coefficient over rural Area near Beijing mega-city [J]. Atmos. Chem. Phys., 9 (75), 19, 2009. 